\title{
Projeto FLORAM: estratégias e plano de ação
}

ANTONIO S. RENSI COELHO, AZIS AB 'SÁBER, GERALDO FORBES, JACQUES MARCOVITCH, JAMES WRIGHT, JOSÉ GOLDEMBERG, LEOPOLD RODÉS, LUIZ G. BARRICHELO, MAURO ANTONIO DE MORAIS VICTOR, NELSON BARBOSA E WERNER ZULAUTF

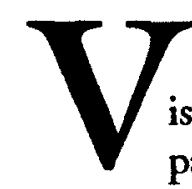

isando estabelecer critérios estratégicos de caráter geral para orientar as propostas relativas às atividades a serem eventualmente incluídas nos planos de açáo do Projeto FLORAM, foram elaborados e discutidos critérios para os seguintes temas:

- Reversão do efeito estufa.

- Conservaçáo dos ecossistemas regionais.

- Reflorestamento e uso do solo.

- Reflorestamento em nível de desenvolvimento industrial.

- Uso energético da madeira.

- Instituiçóes, Empresas, Cooperativas.

A metodologia seguida e a subdivisão dos temas estratégicos, acima listados, foram inspiradas no documento Tropical Foresty Action Plan da FAO. Assim sendo, o delineamento dos critérios estratégicos recomendados constitui uma adaptação daqueles que constam no documento da FAO, visando as condiçóes e peculiaridades florestais específicas do Brasil. 

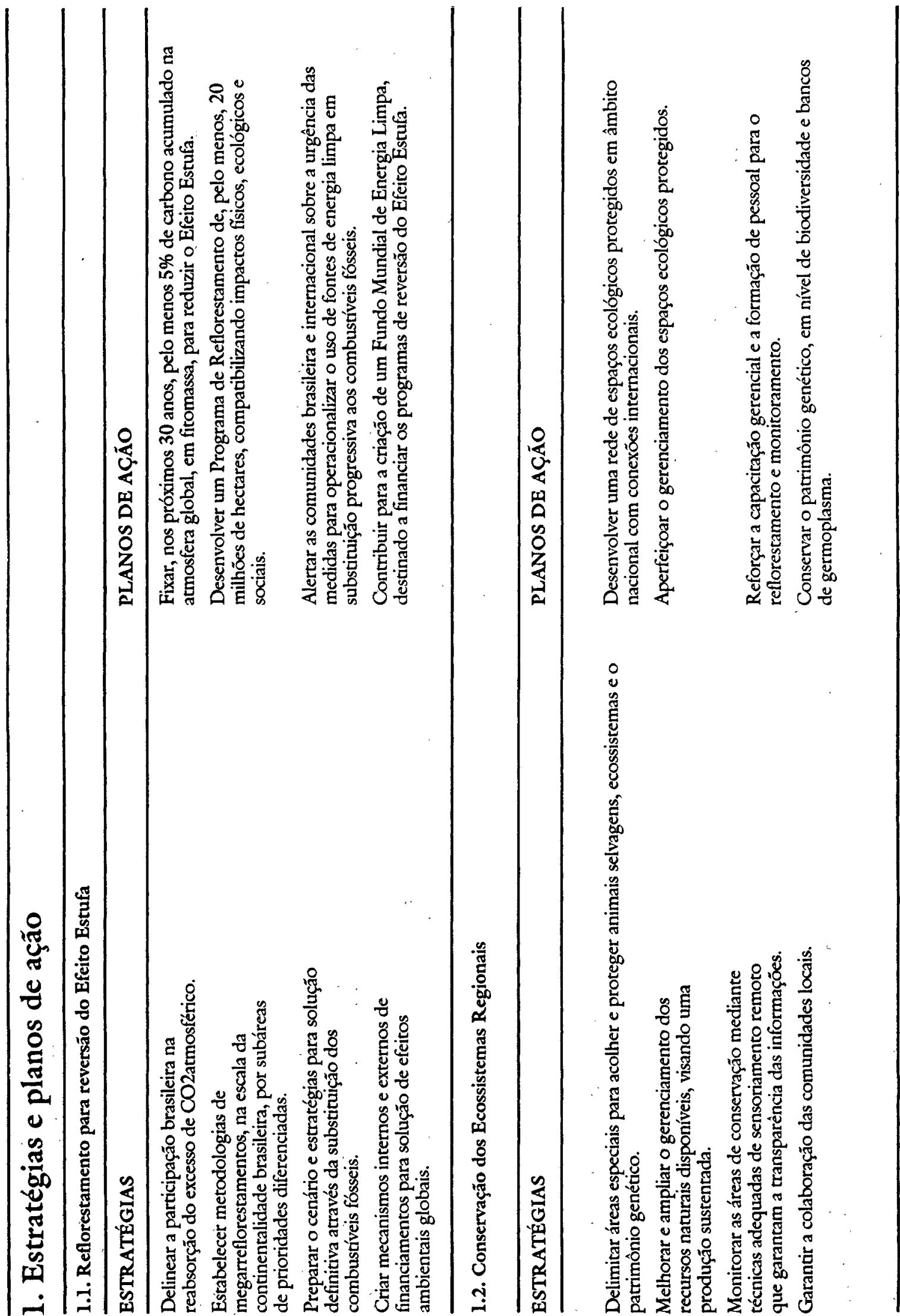

Estudos Avançados, 4(9) 


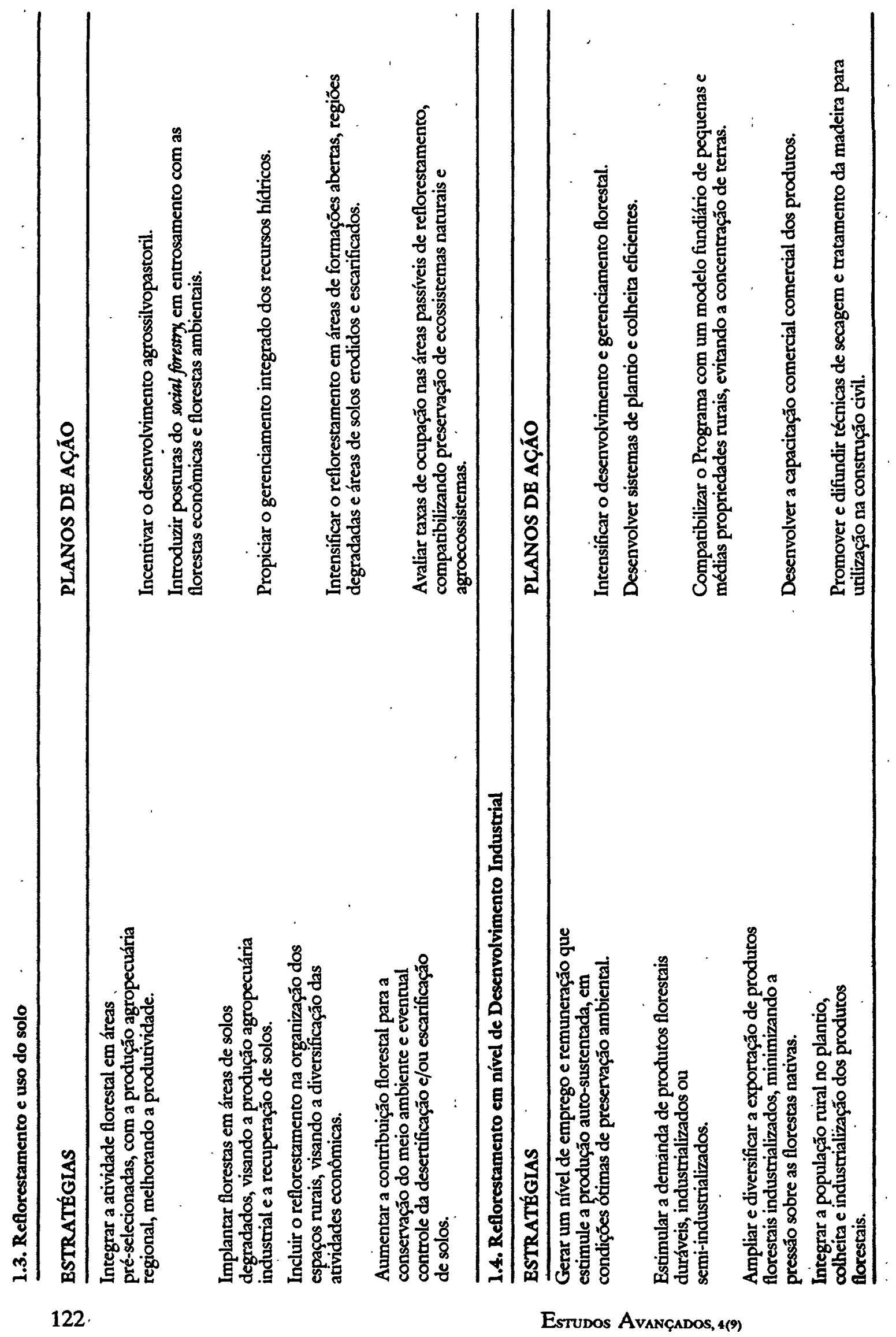




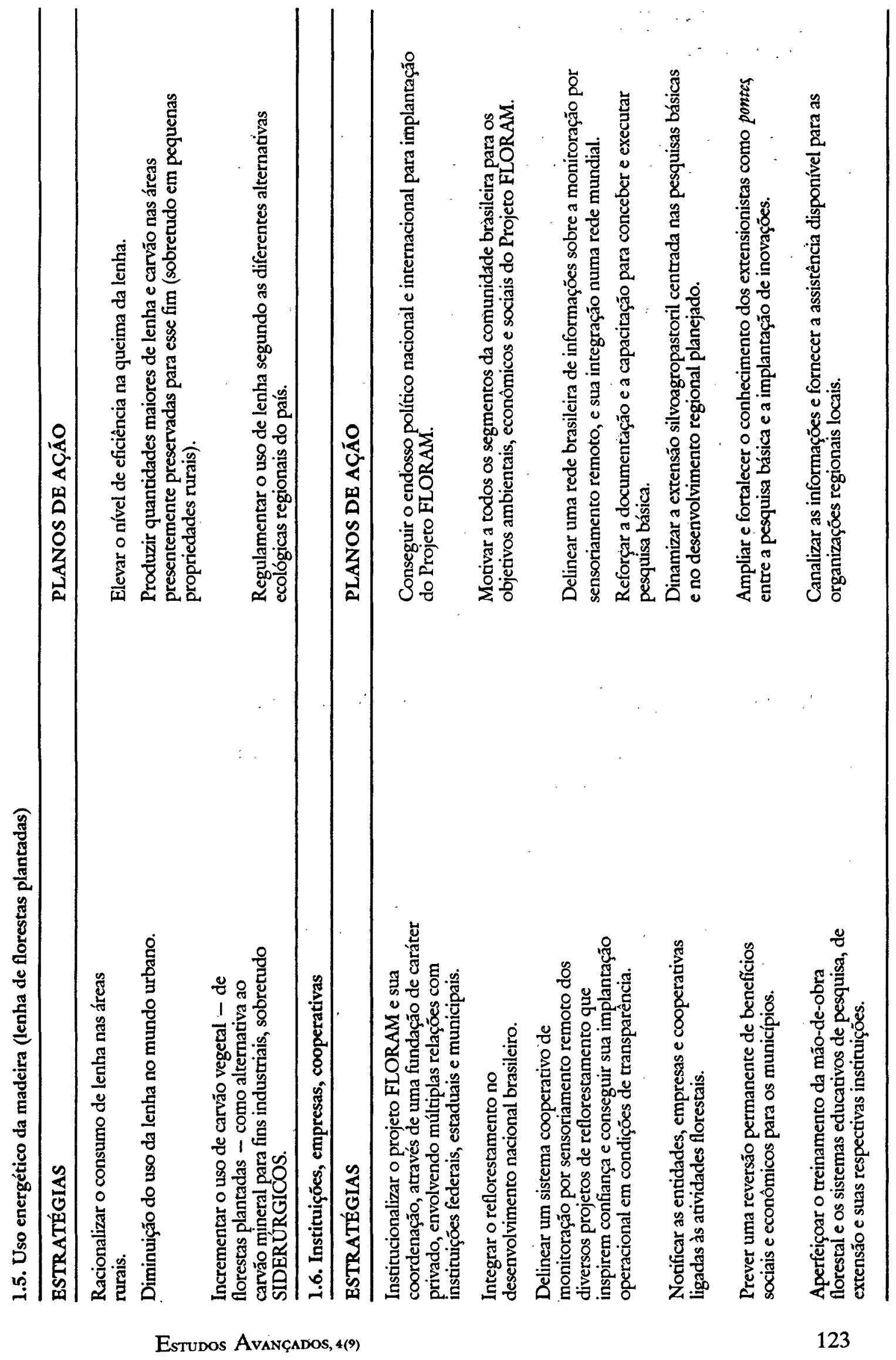




\section{Estratégias diferenciadas por domínios e espaços regionais}

Os critérios estratégicos de caráter geral, estabelecidos de acordo com a metodologia acima apontada, propiciaram diversos conjuntos de recomendações estratégicas diferenciadas, em decorrência da sua especificidade em relação a um ou mais de um dos espaços considerados.

Os conjuntos diferenciados de recomendaçóes estratégicas são os seguintes:

1. Domínios ecológicos, espaços regionais e taxas de ocupação: previsão de impactos ambientais.

2. Estratégias para o reflorestamento no domínio das pradarias mistas do Rio Grande do Sul (Coxilhas).

3. Estratégias para o reflorestamento no domínio das araucárias.

4. Estratégias para o reflorestamento no domínio dos cerrados.

5. Estratégias para o reflorestamento diferencial no Brasil Tropical Atlântico (Mar de Morros).

6. Estratégias para o reflorestamento nos sertóes do Nordeste seco.

7. Estratégias para o reflorestamento de áreas críticas da Amazônia.

8. Estratégias para preservação e usos contidos em áreas de refúgios florestados: brejos nordestinos e capóes de matas no Brasil Central.

9. Estratégias para rearborização de áreas urbanas e periurbanas.

10. Estratégias e diretrizes para proteção da beira de reservatórios e seu contorno. 


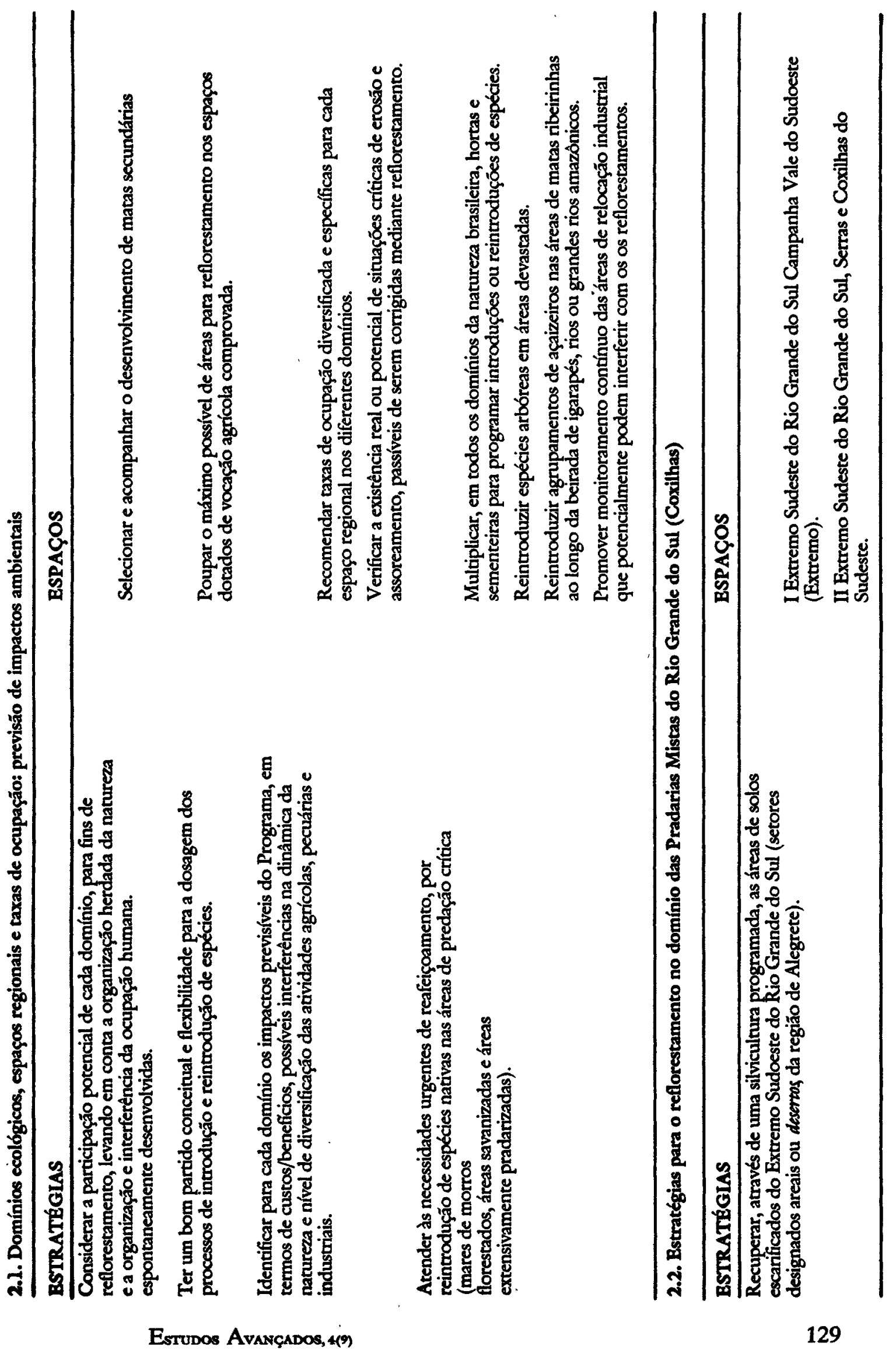



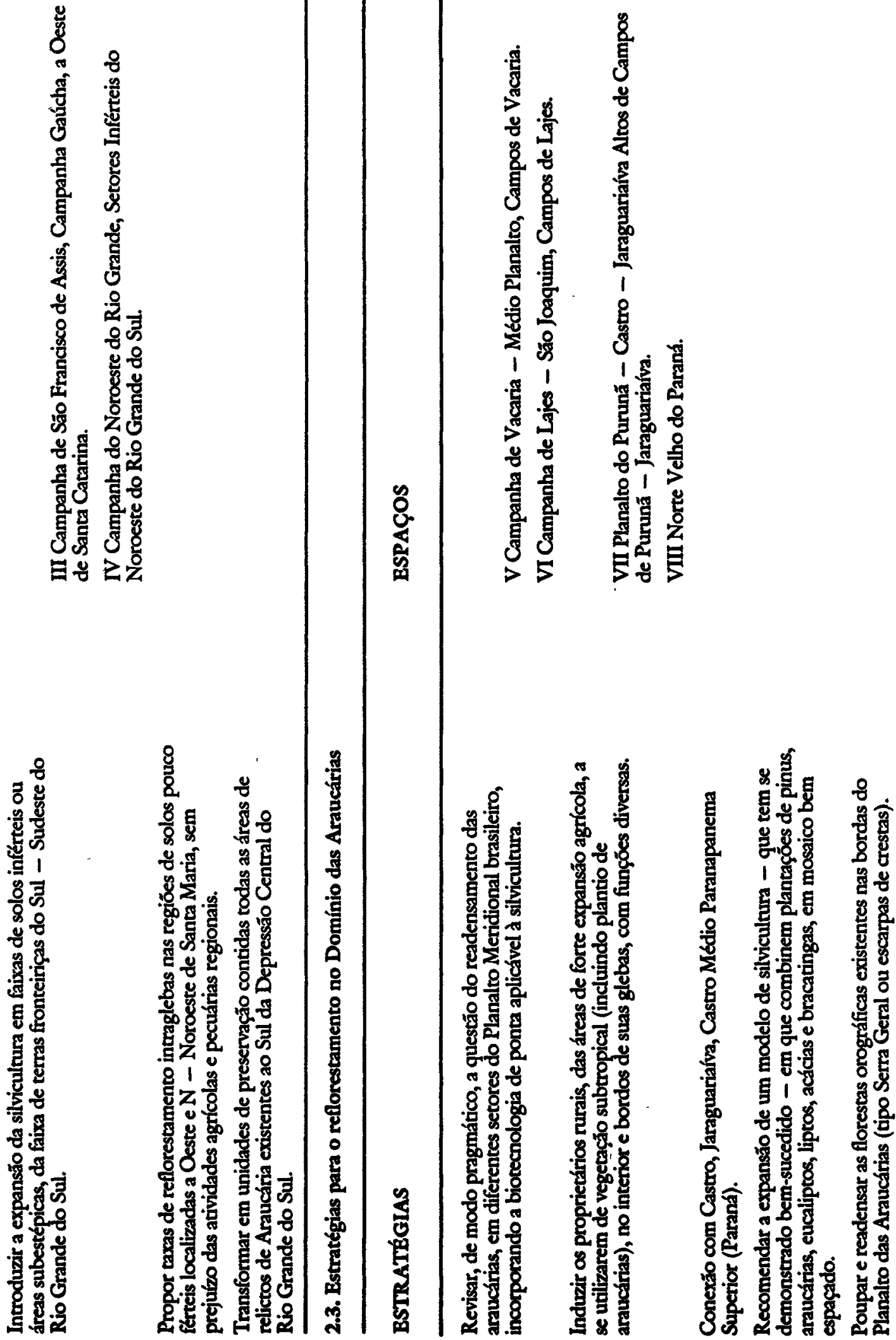







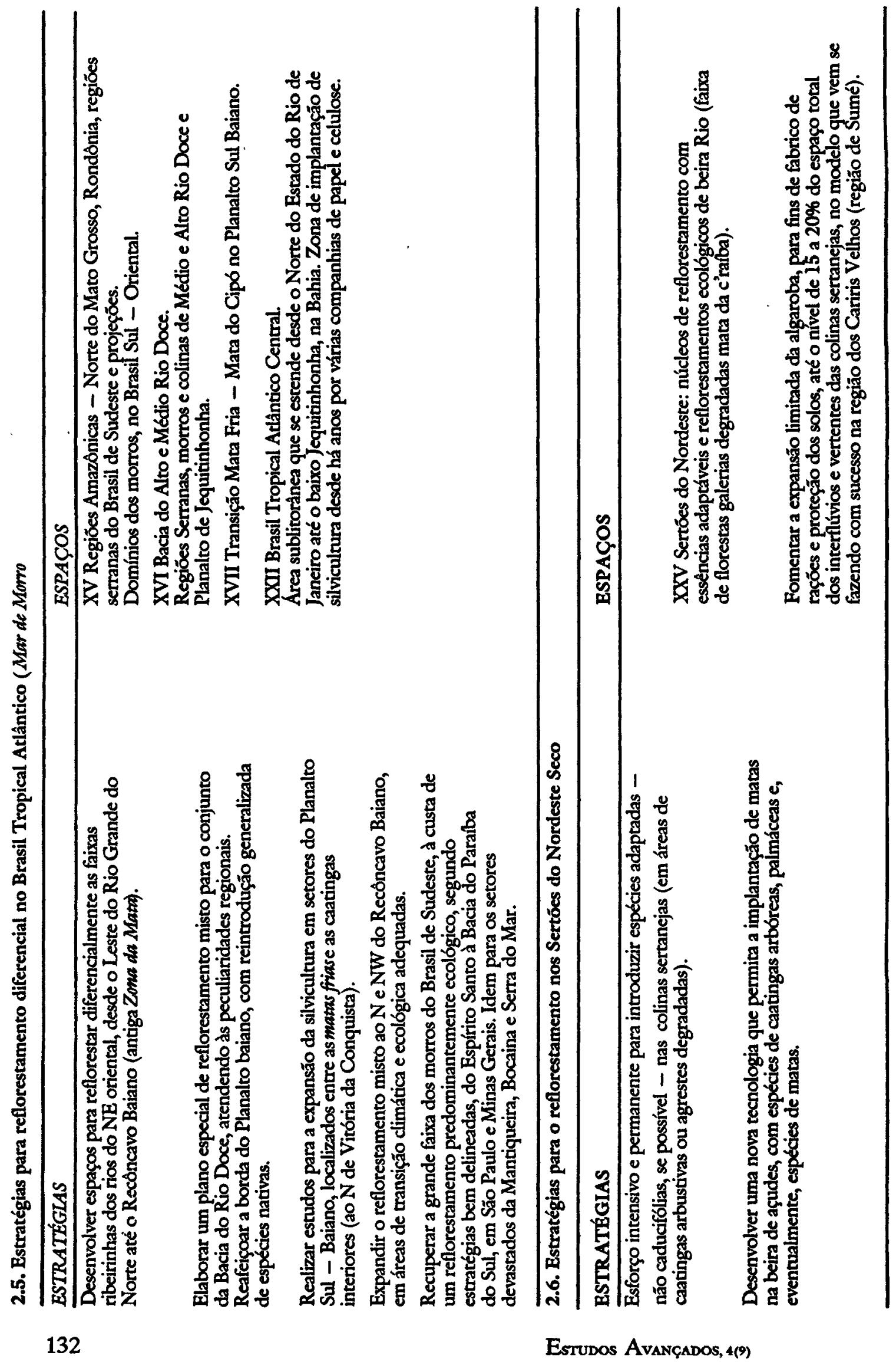




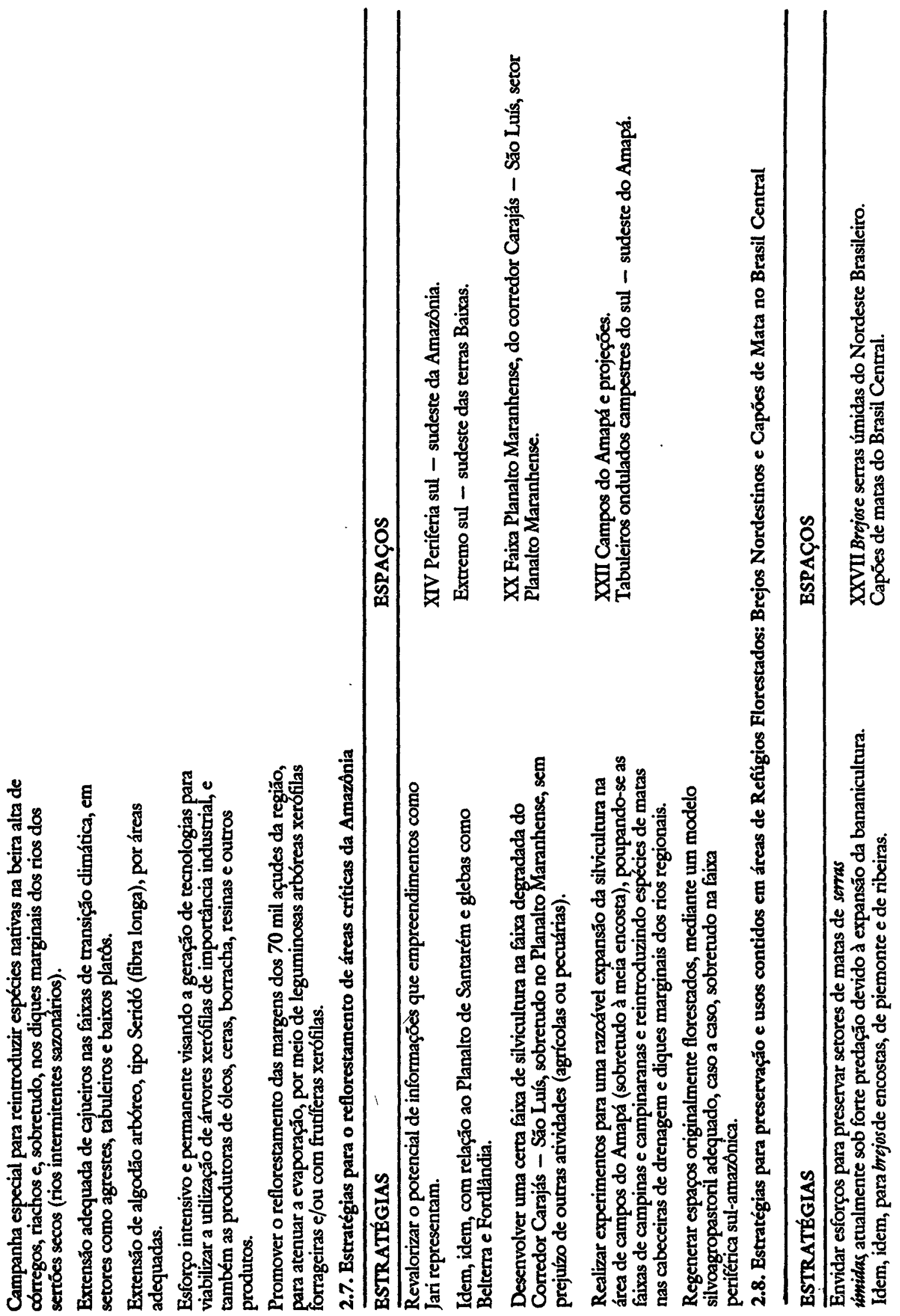




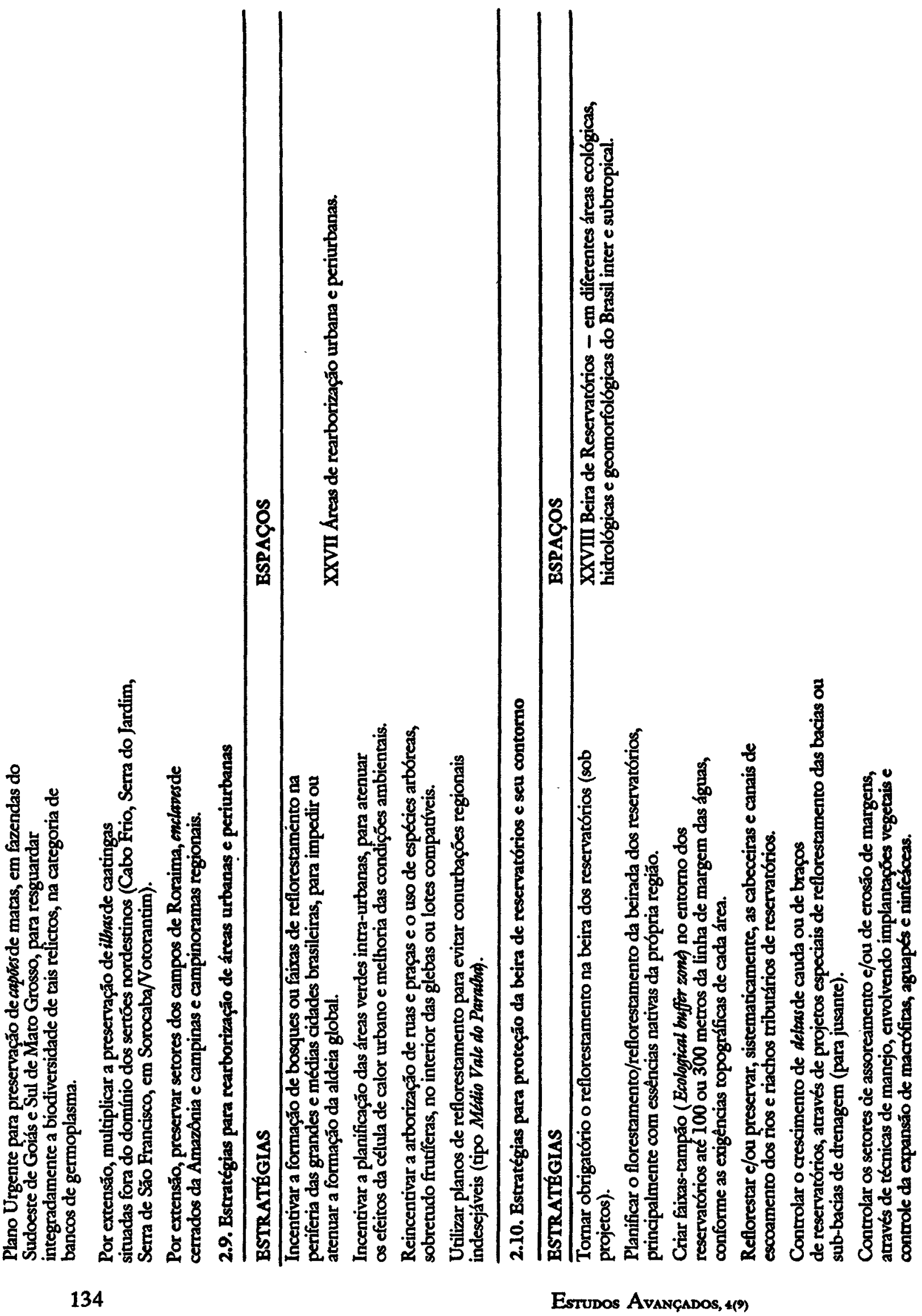




\section{Composição multidisciplinar das linhas de ação consideradas}

O presente estado do delineamento para o Projeto FLORAM e seus objetivos permite antever uma série de prováveis desdobramentos em subprojetos de caráter essencialmente multidisciplinar e de cuja execuçāo satisfatória dependerá, em grande parte, o sucesso e o nível de eficácia conseguida no atingimento dos objetivos maiores do projeto principal.

Sem pretender ser uma relaçáo exaustiva, apresentamos a seguir as grandes avenidas abertas às providências executivas esperadas do Projeto FLORAM e sobre as quais apresentamos alguns comentários.

- Planejamento Estratégico. Deverá permitir elaborar uma visăo abrangente do Projeto FLORAM como um todo, mediante a utilização e subseqüente integração das diversas percepçóes estratégicas com caráter e fundamentaçáo regional, quando cruzadas com.os planejamentos estratégicos elaborados pelos principais setores industriais envolvidos. O mecanismo integrador deverá também compatibilizar as estratégias de reflorestamento e industrializaçăo dos produtos florestais com as de outros planejamentos paralelos, tais como das atividades agropecuárias e as do setor industrial considerado como um todo. Esta compatibilizaçáo refere-se principalemente às questóes energéticas e outros insumos.

- Coordenafaco de $P+D$ e Difusáo das Informafóes. Pelo caráter pioneiro do Projeto FLORAM, existe um grande número de áreas demandando levantamentos dentro de um programa de Pesquisa e Desenvolvimento Tecnológico. Destacam-se como temas prioritários os seguintes:

- Geomorfologia e geoecologia dos espaços regionais

- Condicionantes pedológicas e geoidrológicas superficiais

- Biotecnologia silvicultural

- Fisiologia vegetal da reproduçáo e crescimento

- Eficiência fotossintética

- Flutuaçö́es climáticas

- Sensoriamento remoto

- Alternativas de industrialização para os produtos da floresta

- Fornecimento de sementes/mudas e sua preparaçáo

- Controle biológico

- Gerenciamento e manejo 
No estabelecimento das prioridades executivas será necessário auscultar atentamente as demandas de $\mathrm{P}+\mathrm{D}$ ligadas à execuçăo de reflorestamentos e aos seus aspectos essencialmente regionais. Deverá também ser aperfeiçoada a metodologia de avaliação de riscos futuros (ecológicos e sociais), decorrentes de iniciativas humanas aparentemente inócuas.

A difusão das informaçóes geradas mediante as atividaes de $\mathrm{P}+\mathrm{D}$ deverá ser conseguida pelo acesso a terminais estrategicamente localizados e alimentados mediante uma rede informática conectada a bancos de dados continuamente atualizados.

- Alternativas Institucionais. Ao redor das consideraçóes apresentadas neste documento, caberá abrir um amplo diálogo visando identificar as vantagens e os inconvenientes de uma eventual continuidade institucional nas atividades iniciadas sob a denominaçăo de Projeto FLORAM.

A engenharia organizacional deverá identificar alternativas para configurar uma estruturaçăo leve, essencialmente orientadora e indutora de convergência nos esforços para uma correta implantaçáo, respeitando os sucessivos desdobramentos em projetos multidisciplinares do objetivo maior.

De modo natural, visualiza-se o Instituto de Estudos Avançados da USP como ponto de encontro para fecundaçáo e enriquecimento mútuo das disciplinas intervenientes $e$, assim sendo, visualiza-se uma participação ativa na continuidade de sua funçáo de assessoramento institucional.

A estrutura institucional deverá atender às necessidades administrativas decorrentes da coordenação e compatibilizaçăo dos planejamentos estratégicos, tanto setoriais como regionais; à coordenaçáo das prioridades nos levantamentos de $\mathrm{P}+\mathrm{D}$; à supervisão da eficiência operacional da rede de informática que deverá difundir os resultados $e$ eventuais recomendações; à monitoração executiva dos reflorestamentos, mediante sensoriamento remoto, oferecendo uma transparência absoluta nas informaçóes e avaliaçóes geradas; $\mathrm{e}$, finalmente, deverá atender os controles dos investimentos, incentivos, despesas operacionais e administrativas, contempladas em orçamentos aprovados e cuja elaboraçáo seria uma das tarefas administrativas principais.

Os mentores do Projeto estáo atentos para a circunstância da rotina administrativa altamente burocrática e entravante, que predomina nos 
mais diferentes níveis das máquinas de governo, em seus mais diferentes escalōes. Năo se fará concessóes a indivíduos ou grupos inoperantes e mordômicos, fixados na inércia histórica de determinadas máquinas, eivadas de nepotismos e hábitos corruptos.

\section{Consideraçóes para uma abordagem institucional}

O Projeto FLORAM, na medida em que trata de uma ação de megarreflorestamento, deverá contar com um suporte institucional que assegure a conservação dos objetivos colimados, levando na devida conta a flexibilidade operacional que um projeto nessa escala requer e, ao mesmo tempo, garanta que a ideologia básica do projeto, bem caracterizada neste primeiro documento, permeie as açóes de plantio, conservaçáo e manejo das florestas a serem executadas em todo o território nacional.

... o Projeto

FLORAM terá que escolher a sua

paternidade institucional, sob

grande

flexibilidade $e$ bom senso, através de múltiplas combinaçōes de participação.

No nível de consolidação que os estudos atingiram ao final de 1989 (um ano depois da primeira manifestação pública sobre a conveniência do reflorestamento como instrumento de absorçáo de carbono da atmosfera, e oito meses desde a sua adoçáo pelo Instituto de Estudos Avançados), o projeto pode ser considerado como um embriāo, ainda unicelular, mas dotado de todas as particularidades fisionômicas e estruturais do produto final a ser alcançado nos próximos anos não apenas no Brasil, mas necessariamente em uma escala de abrangência mundial, para que seja alcançado seu objetivo maior, o controle do "efeito estufa".

No contexto do grande debate em curso entre estatizaçáo e privatizaçáo, também o Projeto FLORAM terá que escolher a sua paternidade institucional, sob grande flexibilidade e bom senso, através de múltiplas combinações de participação.

A grandiosidade do Projeto torna-lo-á, obrigatoriamente, instrumento de reversão da imagem ambientalmente dura que o Brasil possui no Exterior, năo pelo que se diz e se escreve - as queimadas da Amazônia seriam as maiores responsáveis pelo "efeito estufa" (sic) -, mas pelos erros que realmente temos cometido ao permitir uma destruiçăo da biodiversidade de ecossistemas inteiros e sinalizar para a desertificação ou savanizaçáo de extensa áreas de nosso território.

O Projeto FLORAM poderá vir a ser, portanto, um instrumento sério e denso para ajudar o Governo a compor o seu quadro de política internacional para as questóes ambientais. Esse conteúdo de interesse 
para a diplomacia poderá favorecer a sua institucionalizaçáo governamental. A divulgaçăo prévia dos objetivos do projeto já comprovou esta asserçáo.

Por outro lado, o nível de agilidade para captar e canalizar recursos financeiros em grande monta e a tendência mundial de se prestigiar as organizaçóes năo-governamentais (NGO) recomendam o caminho da privatização.

O fator predominante na composiçáo dessas tendências (de onde emergirá o modelo institucional do Projeto FLORAM) deverá ser aquele que se acentua em todo o mundo, inclusive no Leste Europeu, de permitir que a agilidade $\mathbf{e}$ a produtividade das instituiçóes privadas comandem um número crescente de açóes nos diversos campos da atividade humana.

Diante de tais tendências, convém considerar uma Fundação năo instituída pelo poder público, ou outra forma organizacional de cunho privado, como unidade central para o desenvolvimento dos projetos técnicos e estudos ambientais e econômicos, bem como para motivar a implementaçáo das práticas de florestamento e reflorestamento preconizadas, e gerenciar financiamentos de instituiçōes nacionais e internacionais destinados ao projeto.

Além dos colegiados destinados à administraçáo exigidos pela legislação, deverá ser criado um Conselho Orientador, constituído de personagens de notório saber, onde estará representada a instituiçáo que gerou o Projeto, o Instituto de Estudos Avançados da USP.

Integrando a diretoria executiva da Instituiçáo, deverá ser estabelecida uma sólida unidade de captação de recursos para a implementaçáo do projeto. Num primeiro momento e objetivando fundamentalmente a implantaçáo das florestas com finalidades predominantemente econômicas, deverão ser estimulados os investimentos pelos próprios setores usuários das matérias-primas geradas. Estes setores deverão também financiar a estruturaçáo inicial do orgáo de gerenciamento e os primeiros projetos detalhados das açóes que compóem o Projeto FLORAM.

Já que todos os reflorestamentos satisfazem o objetivo ambiental maior, que é a fixação de carbono visando a reversão do efeito estufa, deverão ser buscados recursos em bancos internacionais de desenvolvimento (BIRD, BID, entre outros), para as florestas com mais forte vocaçáo ecológica clássica. 
A dimensão mega do Projeto FLORAM deverá exigir o aporte de recursos vultuosos, náo apenas para atender aos interesses brasileiros do Projeto, mas certamente para atender a demanda internacional, caso o projeto venha a atingir o tamanho imaginado pelos seus criadores e chegue a funcionar como reservatório para reter o excesso de carbono acumulado na atmosfera.

Para essa dimensáo de demanda de recursos não existe previsão de fundos no concerto da ordem econômica internacional, como também não existem para os investimentos destinados à revolução tecnológica decorrente da transformação dos atuais geradores de energia, à base de combustíveis fósseis, para geradores isentos de carbono, como a energia solar acoplada à tecnologia do hidrogênio (Anexo).

Para ser criado um fundo que possa dar suporte a todas essas demandas, basta um movimento mundial, fomentado $\mathrm{e}$ administrado pela $O N U$, que proponha e viabilize uma taxa de cerca de um dólar por barril de petróleo, ou equivalente, no caso de carvão mineral e do gás natural. A dificuldade toda está na motivação para um empreendimento dessa magnitude, não por falta de elementos de comunicação, já que as perspectivas apocalípticas os fornecem em quantidade suficiente, mas por falta de um elemento aglutinador das angústias dispersas.

O Projeto FLORAM pretende ser o núcleo desse processo convergente, pois somente conseguirá atingir seu objetivo maior se provocar o início das reaçóes em cadeia que deverão levar à reversáo do "efeito estufa", reforçando o caminho e as intençóes táo bem caracterizadas na Convenção de Viena e no Protocolo de Montreal, cujos compromissos entraram em vigor recentemente, visando a outro objetivo global: o controle da reduçáo da camada de ozônio estratosférico.

Ao nível técnico, a Fundaçáo deverá compor uma eficiente e multidisciplinar equipe profissional, onde a qualidade dos recursos humanos deverá se impor sobre a quantidade. Os projetos técnicos, as pesquisas e as açóes florestais deveráo ser, sempre que possível, contratadas com empresas especializadas do setor privado.

As idéias aqui expostas nada têm de definitivo. Trata-se, apenas, de enunciar alguns caminhos, sobre os quais ainda não existe total consenso. E, por essa razão mesma, são meras sugestóes preliminares a serem melhoradas, ou, na pior das hipóteses, totalmente modificadas. 


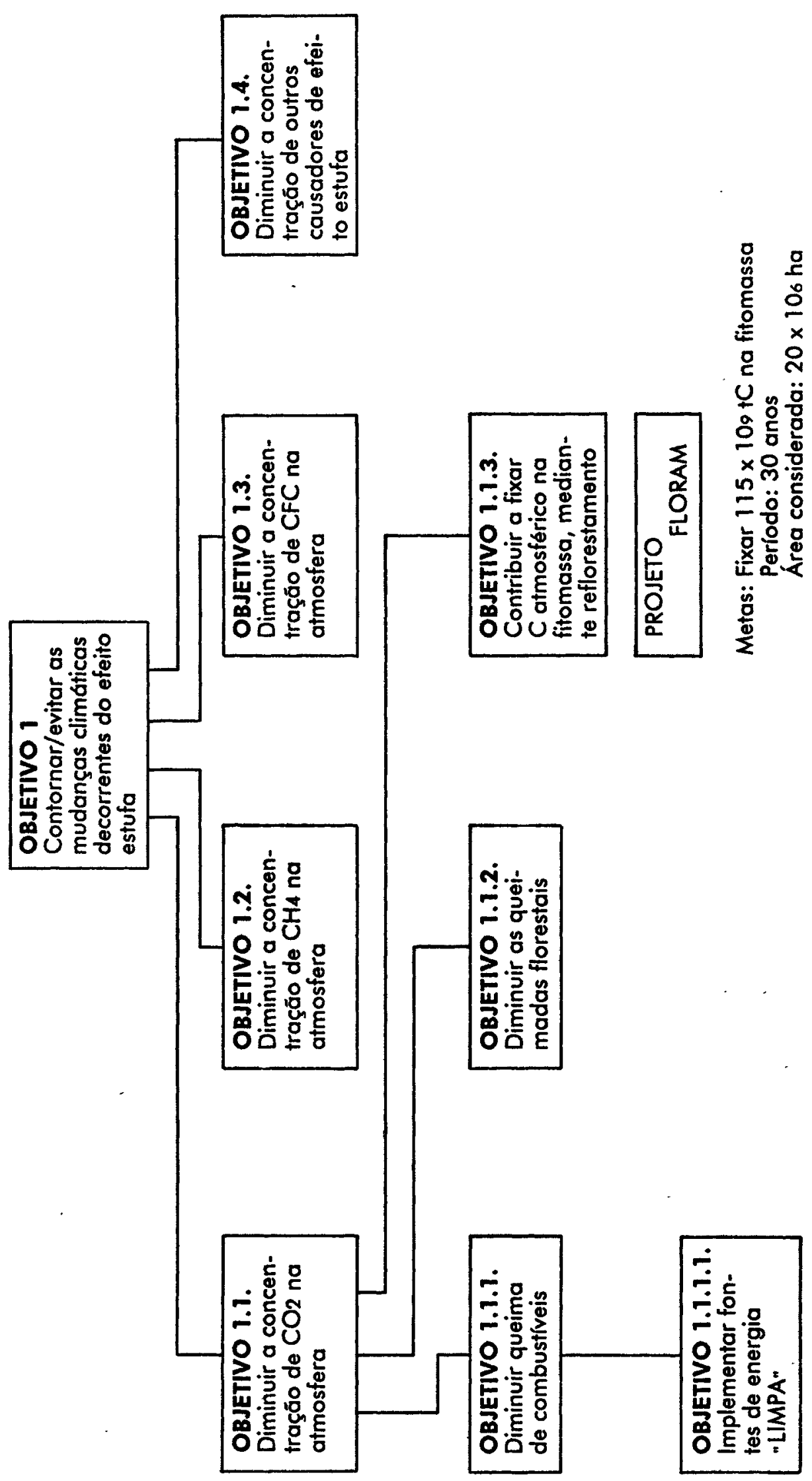


ANEXO A

ESQUEMA DE INSTITUCIONALIZAÇĀO



(*) Fundo Internacional a ser criado 
AB'SÁBER, Aziz Nacib

1971 - A organizafão natural das paisagens inter e subtropicais brasileiras. - In: III Simpósio sobre o Cerrado, 1971, pp. 1-14, Ed. da USP e Ed. E. Blücher Ltda., São Paulo.

\section{1 - Dominios morfoclimáticos atuatise quaternatrios na regiäo dos cerra- dos. - Craton \& Intracraton, n.14, IBILCE-UNESP, São José do Rio Preto, SP.}

\section{ALMEIDA, Álvaro Fernando de \\ 1978 - Conservagáo da fauna silvestre em florestas implantadas. - Bol. Inform. IPEF, vol.6, n. 19, pp. 83-94.}
1982 - Controle integrado de sauipas na Arucruz Florestal. - Aracruz Florestal, Aracruz.
1985 - Planejamento ambiental no ma- nejo florestal: manutencato da pro- dutividade. - Espaço Florestal, ano 1, n.2, pp. 50-60, Porto Alegre, RS.

ALMEIDA, D. G. de

1946 - Madeiras imunes on muito resistentes an cupion. - Revista Florestal, vol.5, n.2, pp. 13-23.

ALMEIDA, D. G. de e COSTA, J. R. da 1956 - Madeiras do Brasil. - Serv. de Econ. Rural, Ministério da Agricultura, Rio de Janeiro.

ARANHA PEREIRA, J e MAINIERI, G. 1949 - Madciras do Brasil. - Anuário Brasileiro de Economia Florestal, vol.2, n.2, pp. 285-351, Rio de Janeiro.

\section{BARRICHELLO, Luiz Ernesto George}

1974 - Caracteristicas da celulose de cmbaúba. ESALQ/USP/DS, Piracicaba, SP.
1978 - Apropeitamento de madeiras de florestas naturais do Estado de Santa Catarina para a produção de celulose. ESALQ/USP, Piracicaba, SP. (Trab. apres. no XI Congr. da ABCP).

BARRICHELLO, L. E. G. e BRITO, J. O.

1982 - Celulose sulfato branqueada de bracatinga. Brasil Florestal, ano 12, n.49, pp. $45-50$ (jan./março de 1982), Brasilia, DF.

BASTOS, A. de $M$.

1951 - O mogno brasileiro. Anuário Brasileiro de Economia Florestal, n.4, pp. 136-141.

BATISTA, J. L. F.

1988 - Apontamentos de Silpicultura Urbana. ESALQ/DCF. Piracicaba, SP.

BRITO, José Otávio

1978 - Uso energetico da madeira. ESALQ/USP. Piracicaba, SP.

1978 - Recursos quimicos e energiticos florestais. ESALQ/DS. Piracicaba, SP.

1981 - Monografia sobre Gmelina arborea. ESALQ/SNP. Piracicaba, SP.

1986 - Madeira para energia: a perdadeira realidade. Silvicultura, ano 11, n.41, pp. 188-193, São Paulo.

CABRERA, A. L. e WILLINK, A.

1973 - Biogeografia de Amtrica Latina. OEA - Depto. de Assuntos Científicos, Washington D.C.

CAPPANEZZI, A. A. e LAURENT, J. E. (Coords.)

$$
\begin{aligned}
& 1989 \text { - Manual Técnico da Bracatinga } \\
& \text { (Mimosa scabrella Benth). } \\
& \text { EMBRAPA-CNPF (Docu- } \\
& \text { mento n.20), Curitiba. }
\end{aligned}
$$

\section{CARVALHAL, C. $M$.}

1979 - Generalidades sobre a fixafäo e consolidafato de dunas com pegetacälo: fixcafato de dumas - processos cmpregados. AGROS, vol.14, n.2, pp. 129-137, Pelotas.

Estudos Avançados, 4(9) 
CAVALCANTE, M. S.

1982 - Deteriorafä̃o biológica e preservafăo de madeiras. Publ. IPT, 1211. Inst. de Pesqs. Técns., Sāo Paulo.

1983 - Implantafão e desenvolvimento da preservafăo de madeiras no Brasil.Publ. IPT, 1234. Inst. de Pesqs. Técns., São Paulo.

1984 - Durabilidade natural de madeiras em contato com solo. (II) Publ. IPT, 1409. Inst. de Pesqs. Técns., Săo Paulo.

CIANCIULLI, P. L.

1959 - $A$ introdufã̃o e aclimafä́o do Pinus Elliotti e outras conifferas no Estado de São Paulo. Anuário Brasileiro de Economia Florestal, n.11, pp. 66-89.

CIMI, CEDI, IBASE e GhK

1986 - Brasil: Áreas indigenas e grandes projetos (Mapa na escala de 1.5.000.000). CIMI, CEDI, IBASE e GhK, Brasilia.

CTI/IPEF

1990 - Catallogo de Teses. (Area de Engenharia Florestal - Acervo da Biblioteca "Heládio do Amaral Mello" ). CTI/IPEF, ESALQ/USP, Piracicaba.

ESALQ/USP/DCF

1973-89 - Produçăo Cientifica. Depto. de Ciências Florestais, ESALQ/USP, Piracicaba, SP.

ESALQ/USP/Depto. de Ciências Florestais/IPEF (Bibliografias especializadas - dos professores e técnicos da ESALQ/USP: Alvaro Fernando de Almeida, Luiz Ernesto George Barrichelo, J.L.F. Batista, J.O. Brito, Hilton T. Couto, Luiz Carlos Estraviz Rodrigues, Mário Ferreira, M.R. Giotto, J.N. Garcia, A.N. Gonçalves, I.P. Jankowsky, P.Y. Kageyama, W.de P. Lima, T.C. Magro, Fábio Poggiani, Fernando Seixas, J.W. Simóes, $M$. Tomazello Filho e Virglio Maurício Viana.) ESLQ/USP/DCF, Piracicaba, SP.

FAO - Commitee on Forest Development in the Tropics

1985 - Tropical Forestry Action Plan. FAO. Roma.
FAO - IBRD - WRI - UNDP

1987 - The Tropical Forestry. Action Plan. FAO (e outros). Siena, Itália (Em forma de Cartilha).

FEARNSIDE, Philip $M$.

1986 - Agricultural plans for Brazil's Grande Carajds Program: lost opportunity for sustrimable depelopment? World Development n.14, pp. 385-409.

1988 - O carvão de Carajas. Ciência Hoje, vol.8, n.48, pp. 17-21, SBPC.

FERREIRA, Mário

1978 - Escolba de especies de eucalipto. ESALQ/USP, Piracicaba, SP.

1982 - Terminologia de melboramento gentico florestal. $2^{2}$ ed., EMBRAPA/URPFCS, Curitiba, PR.

FONSECA FILHO, C. de A.

1959 - Essencias para reflorestamento e arborizafáa. Bol. de Agricultura, vol.8, n.5-6, pp. 15-28 e Anais da Soc. Bot. do Brasil XI Reuniāo Anual, I vol., pp. 93-111 (1962), Belo Horizonte.

FUNBRASIL - Fundação Nacional do Pau-Brasil

1989 - Pau-Brasil - A Árnore Nacional. (Manifesto). Recife, PE.

GALVÃO, A. P. M.

1985 - Árpores Fixcadoras de Nitrogéniono Programa Nacional de Pesquisa Florestal. In: "Simpósio sobre fixaçäo de nitrogênio em árvores tropicais", Rio de Janeiro, 1983.

GARCIA, J. N.

1979 - Descrigato de essencias nativas de interesse florestal. Circ. Téc. IPEF n. 58 (agosto 1979), Piracica$\mathrm{ba}, \mathrm{SP}$.

GONÇALVES, Antônio Natal

1980 - Como aumentar a eficiencia da floresta. Silvicultura, ano 2, n.17, pp. 34-39 (nov.-dez. de 1980), São Paulo, SP.

GONÇALVES, J. L. M.

1988 - Interpretafato de levantamento de solos para fins silpiculturais.IPEF, n.30, pp. 65-72, Piracicaba, SP. 
GURGEL FILHO, C. A.

1964 - O comportamento florestal das Conefferas. Silvicultura n.3, pp. 129-188.

GURGEL FILHO, C. A. e ALVARENGA, R. M.

1963 - As pindceas no reflorestamento do Estado de Sto Paulo. Silvicultura em Săo Paulo n.1, pp. 117147.

HENSDIJK, D. L. e SOARES R. D. e BASTOS M.

1962 - Plantagato de confferas no Brsil. Estudo preliminar sobre o volume e - rendimento de Araucaria angustifolia, Cryptomeria japonica, Cunningbamia Ianceolata e Pinus elliottii. Setor de Inventário Florestal, Boletim n.51, Rio de Janeiro.

HÜECK, Kurt

1972 - As florestas da Amćrica do Sul. Ed. Polígono e Ed. da Universidade de Brasilia, Brasilia, DF.

INSTITUTO BRASILEIRO DE DESENVOLVIMENTO FLORESTAL

1974 - Zoneamento Económico Florestal do Estado de Minas Gerais.IBDF. Min. da Agric. BR., Belo Horizonte.

1974 - Zoneamento Economico Florestal do Estado do Espirito Sarto.IBDF. Minist. da Agr. BR., Belo Horizonte.

INSTITUTO BRASILEIRO DE DESENVOLVIMENTO FLORESTAL - DF

1985 - Programa de Monitoramento da Cobertura Florestal do Brasil. Al. teragtio da Cobertura Vegetal Natural da Regiato Amazdnica. Braslia, DF.

\footnotetext{
INSTITUTO ESTADUAL DE FLORESTAS/IEF

1986 - Controle da exploractio florestal an Minas Gerais. Período janeiro/80 a junho/85, Belo Horizonte.
}

INSTITUTO FLORESTAL - Coord. da Pesq. de Recursos Naturais

1975 - Zoneamento Economico Florestal do Estado de Sáo Paulo. Secr. Agric. de SP., Boletim Téenico n.17, CPRN, São Paulo.

1975 - Attas do Zoneamento Ecombinico Florestal do Estado de Sáo Paulo. Atlas/Anexo do Boletim Técnico n.17, Secr. da Agric. de SP., IF-CPRN, São Paulo.

JANKOWSKY. Ivaldo $P$.

1982 - Ensino da preservafáo de madeiras nos cuersos de Engenbaria Florestal. Săo Paulo, SP.

1982 - Secagem natural de madeira rolisa com casca. ESALQ/DCF/EPEF. Piracicaba, SP.

JANKOWSKY, I. P. e OLIVEIRA, L. C. S. 1964 - Tratamento prepentipo e secagem de madeira de "Pinus" ssp.Publ. IPT, 1517. Inst. de Pesqs. Técns., São Paulo.

JORDAN, C. F. e RUSSELL, C. E.

1983 - Jari: prodsuctividad de las plantaciones y perdida de nutrientes debido al corte y la quema. Interciência vol.8, n.6, Pp. 294-297.

KAGEYAMA, Paulo Yoshio

- Crittrios de escolba de espécies para utilizafato an pequerras dreas de reflorestamento. IBDF. São Paulo.

1969 - Agentes biologicos da deteriorafáo das madoiras: fungos sailofagos 0 manchadores. Piracicaba, SP.

1975 - Banco de clones de pinus tropicais: aspectos da frase de enscertia. Bol. Inform. IPEF, ano 3, n.10, Pp. 42-52, Piracicaba, SP

1981 - Saturafelo dos reflorestamentos de Pinus no Brasil. IPEF, Piracicaba, SP. 
1984 - Fatores que afetam a produfẵo de sementes florestais. IPEF. Piracicaba, SP.

1989 - Plantafóes de especies natipas: florestas de protefäo e reflorestamento misto. ESALQ/DCF. Piracicaba, SP.

KAGEYAMA, P. Y. e DIAS, I. de S.

1982 - Aplicaçäo da genética em espécies florestais nativas. Silvicultura em São Paulo, 16A (parte 2), pp. 782-791, São Paulo.

KAGEYAMA, P. Y. e CASTRO, C. F. A.

1986 - Conservacáa gentetica in situ c uso múltiplo da floresta. Silvicultura, ano 11, n.41, pp. 77-80, São Paulo.

KLEIN, R. M.

1966 - Árpores natipas indicadas para o reflorestamento no Sul do Brasil. Sellowia, n.18, pp. 29-39.

KRUG, H. P.

1964 - O plantio de Pinus em São Paulo. Anuário Brasileiro de Economia Florestal, n.16, pp. 259 295.

LIMA, Walter de Paula

1975 - Estudo de alguns aspectos quantitativos e qualitativos do balango bidrico em plantaçóes de cucaliptos - Pinus. Tese de Doutorado. ESALQ/USP, Piracicaba, SP.

1980 - Asflorestas e a poluifaño do ar. Sér. Técn. IPEF. ano 1, n.1, Pp. 143, Piracicaba, SP.

1985 - Açăo das chuvas no ciclo biogeoquimico de nutrientes em plantafóes de pinheiros tropicais em cerradăo. IPEF, n.30, pp. 13-17, Piracicaba,SP.

1985 - Hidrologia de florestas implantadas. Documentos. EMBRAPA/CNFP, n.16, pp. 8-13, Curitiba, PR.

1986 - O Eucalipto, a dgua e o solo. Seminário.ESALQ/DCF. Piracicaba, SP.

1987 - O reflorestamento com eucalipto e seus impactos ambientais. ARTPRESS. São Paulo.
LUCIETO, D. A.

1969 - Identificação e utilidades das especies do gênero "Eucalyptus" cm Säo Leopoldo. Univ. do Vale do Rio dos Sinos.

MAACK, Reinhard

1947 - Breves noticias sobre a geologia dos Estados do Parand e Santa Catarina. Arquivos de Biologia e Tecnologia PR., vol.2, pp. 63154, Curitiba.

MAINIERI, C.

1958 - Madeiras do Brasil. Anuário Brasileiro de Economia Florestal, n.10, pp. 5-108.

MAINIERI, C. e PEREIRA, J. A.

1965 - Madeiras do Brasil. Anuário Brasileiro de Economia Florestal, n.17, pp. 135-416.

MAINIERI, C. e CHIMELO, J. P.

1989 - Ficbas de Caracteristicas das Madeiras Brasileiras. $2^{\mathrm{a}}$ ed., IPT Div. de Madeiras, São Paulo.

MELLO, H. A. e SIMÓES J. W. e BRASIL, U. M. e FERREIRA, C. A.

1976 - Efcito da especic, espacamento e idade de corte sobre a producfão de madeira de eucalipto para celulose. IPEF, 12.

MESA-REDONDA SOBRE REABILITAÇÃO DE ÁREAS MINERADAS DE XISTO

1986 - Mesa-Redonda (...) (27/28 de nov. de 1986). Săo Mateus do Sul, PR.

MUTHOO, M. K.

1977 - Perspectivas e tendéncias do setor florestal brasileiro, 1975 a 2000. - IBDF, 2 vols. Sér. Técn. 8. Brasilia.

NAVARRO DE ANDRADE, E.

1941 - The Eucalyptus in Brazil. Journ. of Heredity, vol.32, n.7, pp.215-220.

1961 - O Eucalipto. - $2^{2}$ ed., Comp. Paul. de Estradas de Ferro. São Paulo. 
NAVARRO SAMPAIO, A.

1951 - Aqlicafóes da madeira de cucalipto. - Anuário Brasileiro de Economia Florestal, n.4, pp. 79-94.

PARENTE, E.

1966 - Plantas de palor econbmico no Ceard. - Fortaleza.

PEREIRA, J.A. (e) MAINIERI, C.

1957 - Madeiras do Brasil. - $2^{2} \mathrm{ed}$, Anuário Brasileiro de Economia Florestal, n.9, pp.5-170.

PICCOLO, H,L.G.

1972 - Plants invading plantation of Eucalyptus robusta. - Revista de Agricultura, vol.47. n.2, Pp. 81-85.

POGGIANI, Fábio

1981 - Utilizafäo de esperies florestais de rapido crescimento na recuperacăto de dreas degradadas. Sér. Técn. IPEF, ano 2, n.4, pp.1-26 (jan. de 1981). Piracicaba, SP.

1983 - Aspectos da dindmica de nutrientes e da produsato de biomassa em plantafóes flerestais de pinheiros tropicais. - IPEF. Piracicaba, SP.

1985 - Ciclagem de nutrientes en ecossistemas de plantafö́es florestais de Eucalyptuse Pinus: implicafóes silviculturatis. - Tese de Livre Docência. ESALQ/USP. Piracicaba, SP.

POGGLANI, F. (e) SLMOES, J.W. (e) MENDES Filho, J.M. (e) MORAIS, A.L.

1981 - A utilizanano de espécies florestais de rapido crescimento na recuperafato de dreas degradadas. - IPEF, Sér. Téen., vol.2, n.4, Pp.1-25 (jan. de 1981). Piracicaba, SP.

\section{RANKIM, Judy M.}

1979 - A jloresia trupical como modelo para desenvulpimento ecológico na Amazbria. - Anais do Simpósio sobre Ciências Básicas e Aplicadas. Publ. da ACIESP, n.19, pp 112-121. Sáo Paulo.
RECORD, S.J.

1925 - Schizolobium: a promissing source of pulpwood. - Tropical Woods, vol.2, pp.2-5.

\section{REUNIÃO CONJUNTA IPEF - ASSO-} CIADOS

1982 - Potoncialidades da Regida Nordeste para a Implantafáo de Florestas de Rápido Crescimento. Salvador, BA (Tema básico da reunião).

\section{RIZZINI, Carlos Toledo}

1971 - Ámores e Madeiras Útzis do Brasil - Manual de Dendrologia Brasileira. - Ed. Edgar Blucher (e) EDUSP, São Paulo.

1977 - Ároores e madeiras do Brasil. SUPREN. IBGE. Rio de Janeiro.

\section{RIZZINI, C.T. (e) HERINGER, E.P.}

\section{2 - Preliminares acerca das formagöes pegetais e do reflorestamento no Brasil Central. - M.A. - Serv. de Informs. Agrícs. Rio de Ja- neiro.}

RUDOLPH, V. (e) SIMŐES, J.W. (e) BERGER, R.

1980 - Mancjo de florestas implantadas para muiltiplos produtos. - IPEF, Circ. Técn., n.101 (maio de 1980). Piracicaba, SP.

SANTA CATARINA, Secretaria da Agricultura e Abastecimento

1975 - Estudo das condifócs ecológicas e ecomburicas da produsfato de materia-prima em florestamento o reflorestamento. - IBDF (Distr. Ind. de SC). Florianópolis, SC.

SÃO PAULO - Secretaria da Agricultura

1970 - Programa Florestal de Sáo Paulo. - Secr da Agric. de São Paulo. São Paulo.

\section{SEIXAS, Fernando}

- Explorafáo em plantios de Eucalypeus ssp sob diferentes espafamentos. - IPEF. Piracicaba, SP. 
1981 - Cultura do Bambu. - ESALQ/UDS. IPEF. Piracicaba, SP.

1983 - Aspectos atuais e perspectivas de desenpolvimento em explorafão florestal. - IPEF, Sér. Técn., n.25, pp. 9-14. Piracicaba, SP.

1987 - Explorafão e transporte de Eucaliptus ssp. - IPEF. Piracicaba, SP.

SEIXAS, F. (e) MENDO, J.L.L.

1990 - Teste de implemento para rebaixamento de tocos $\mathrm{c}$ áreas de reforma de povoamento de eucalipto (1). - IPEF, Cir. Técn., n.173 (junho de 1990). ESALQ Depto. Ciêncs. Flors. Piracicaba, SP.

SIQUEIRA, Joésio Deoclécio Pierin

1986 - Visáo Geral sobre os Inventarios Florestais no Brasil. - In: "Simpósio sobre a Caatinga e sua Exploração Racional", pp.217241. Univ. Estad. de Feira de Santana. EMBRAPA. Brasilia, DF.

\section{SIMÓES, João Walter}

- Producáo de madeira em florestas energtricas sob diferentes práticas silviculturais. - IPEF. Piracicaba, SP.

1968 - MEtodos para producão de misdas de cucaliptos. - Tese de Doutorado. ESALQ/USP. Piracicaba, SP.

1971 - Adubacăo mineral na formafăo de mudas de Eucalipto. - IPEF, Sér. Técn., n.2/3, pp.35-49. Piracicaba, $\mathrm{SP}$.

1980 - Produsfăo de madeira para energia. - CATI. Campinas, SP.

1980-1984 - Técnicas de manejo e seu relacionamento com a produfáo c qualidade da madeira de pinbeiros tropicais. - Boletim Informativo PPT, vol.1 (1980), vol.2 (1982) e vol.3 (1984). Piracicaba, SP.
1981 - Formafáa, manejo e explorafẵo de florestas com especies de rapido crescimento. - IBDF. Brasilia, DF.

1983 - Andilise dos métodos silviculturais adotados em florestas implantadas para a produfáo de energia. IPEF. Piracicaba, SP.

SIMŌES, J.W. (e) BRANDI, R.M. (e) MALINOVSKY, J.R.

1976 - Formaxfo de florestas com espécies de rapido crescimento. PRODEPEF, Serv. Div., n.6, pp.I-74. Brasília, DF.

SIMŌES, J.W. (e) FERREIRA, M. (e) GUERRINI, I.A.

1986 - Relatório de visita técnica ds $\mathrm{cm}$ presas florestais da regiäo Norte. - IPEF (aut. de 1986). Piracicaba, SP.

SIMÕES, J.W. (e outros)

1984 - Crescimento e produscüo de madeira de eucalipto. - Revista da Madeira, vol.33, n.385, pp.2331 (jan. 1984).

SIMPÓSIO BRASILEIRO SOBRE TECNOLOGIA DE SEMENTES FLORESTAIS

1989 - Segundo Simpósio Brasileiro (...). São Paulo.

SIMPÓSIO IUFRO SOBRE MELHORAMENTO GENÉTICO E PRODUTIVIDADE DE ESPECIES FLORESTAIS DE RÁPIDO CRESCIMENTO

1980 - Simposio IUFRO (...). agosto de 1980. Aguas de São Pedro, SP.

\section{SIMPOSIO SOBRE MATA CILIAR \\ 1989 - Simpósio Sobre Mata Ciliar. - Instituto de Botânica (1989). São Paulo, SP.}

\section{SIMPÓSIO FLORESTAL DA BAHIA}

1973 - Anais do $1^{\circ}$ Simpósio Florestal da Babia. -IBDF/CEPLAC/ANCARBA - Secretaria de Agricultura (Bahia). Salvador. 
TIGRE, Carlos de Bastos

1964 - Guia para o Reflorestamento do Polggono das Secas. - Ed. Tip. Minerva. Fortaleza, CE.

TOMAZELLO Filho, Mário

1976 - Estrudos sobre o cancro caussado por Diaporthe eubensis Bruner: atiologia e resistencia on Eucalyptus spp. - Tese de Mestrado ESALC/USP. Piracicaba, SP.

1980 - Influbincia dos fiungos ectomicorrtzicos Thelepbor torrestris Ebr. ax. Fr. C Pisothus tenctorius (Pers.) Coker e Couch no desenvolvimento de especies tropicais do Pinus. Tese de Doutorado. ESALQ/USP. Piracicaba, SP.

1982 - Vegetapto brasiloira: morfologia, dendrologia e identificafato de madeiras. - CPRN. Săo Paulo.

\section{VAN GOOR, C.P.}

1965 - Reflorestumento com contferas no Brasil. - Setor de Invents. Florestais, Minist. de Agricultura (BR), bol. n.9,pp.5-58. Rio de Janeiro.
VEIGA, A.A.

1972 - Curso de Atualizafúo Florestal. - $2^{2}$ ed. Instituto Florestal (SP), vol.1. Rio de Janeiro.

VIANA, Virgilio Maurício

1987 - Ecologia de populafóces florestais e recuperagto de dreas degradadas. - Publ. ACIESP, vol.54, n.1, pp.29-39 (abril de 1987). São Paulo.

VICTOR, M.A.M. (e) KRONKA, F.J.N.

(e) NEGREIROS, G.C.

1972 - Epolufuno, estagio atual e perspectivas das florestas exbiticas em Sä́o Pasulo. - Instiruto Florestal, Boletim Técnico IF - n.1. São Paulo.

WYATT-SMITH, J.

1987 - The Management of Tropical Moist Forest for the Sustained Production of Timber. - WWF. IUUCN/IIED. London.

ZENID, J.G. (c) JARA, E.R.P.

1984 - Lenba como fonte de onergio. Publ. IPT. 1520. Inst. de Pesqs. Técns. Sāo Paulo. 